\title{
REVIEW
}

\section{Bench-to-bedside review: Natural killer cells in sepsis - guilty or not guilty?}

\author{
Fernando Souza-Fonseca-Guimaraes, ${ }^{1,2, *}$, Jean-Marc Cavaillon' and Minou Adib-Conquy'
}

\begin{abstract}
Bacterial sepsis and septic shock are complex inflammatory disorders associated with a systemic inflammatory response syndrome. In the most severe cases of infection, an overzealous release of proinflammatory cytokines and inflammatory mediators by activated leukocytes, epithelial cells and endothelial cells, known as a 'cytokine storm', leads to deleterious effects such as organ dysfunction and even death. By the end of the 20th century, natural killer (NK) cells were for the first time identified as important players during sepsis. The role of this cell type was, however, double-edged, either 'angel' or 'devil' depending upon the bacterial infection model under study. Bacterial sensors (such as Toll-like receptors) have recently been shown to be expressed at the protein level in these cells. In addition, NK cells are important sources of interferon- $\gamma$ and granulocytemacrophage colony-stimulating factor, which are pro-inflammatory cytokines necessary to fight infection but can contribute to deleterious inflammation as well. Interestingly, an adaptative response occurs aimed to silence them, similar to the well-known phenomenon of endotoxin reprogramming.
\end{abstract}

\section{Systemic inflammatory response syndrome, sepsis, and natural killer cells}

Systemic inflammatory response syndrome (SIRS) shares the initial clinical characteristics described for sepsis patients and is based on non-specific criteria during daily observations of patients in ICUs [1]. This syndrome (commonly observed in patients after major trauma, burns, and ischemia, among others) might promote sepsis occurrence. Both pathogen-associated molecular patterns (PAMPs) and damage associated molecular

*Correspondence: Fernando.Guimaraes@qimr.edu.au

${ }^{2}$ Current address: Laboratory of Immunology in Cancer and Infection, Queensland Institute of Medical Research, 300 Herston Rd, Brisbane, QLD 4006, Australia Full list of author information is available at the end of the article patterns (DAMPs), as exogenous and endogenous mediators, respectively, can similarly trigger the initial inflammatory response. PAMPs are recognized by innate sensors termed pattern recognition receptors (for example, NOD-like receptors (NLRs), Toll-like receptors (TLRs)). The consequence of this pathogen sensing is the production of pro-inflammatory mediators for the eradication of invading microorganisms, and in parallel the production of anti-inflammatory mediators to control this response [2]. The pro-inflammatory process can induce tissue damage and organ failure, while the antiinflammatory response involves leukocyte reprogramming, a natural phenomenon that renders leukocytes tolerant and hypo-reactive to activating signals in terms of inflammatory contribution while maintaining their anti-infectious properties. The phenomenon has been claimed to possibly lead to increased risk for nosocomial infections [3].

The concept of natural killer (NK) cells was first reported in 1971 by Miller and collaborators [4], and later named and better described by Hans Wigzell's group [5], which established that leukemia cell lines were lysed by cells with the morphology of small lymphocytes and with different T- and B-cell characteristics. Soon after, it was reported that NK cells were also active against virusinfected cells [6]. NK cells are able to induce death of target cells expressing 'nonself' antigens or inaccurate levels of major histocompatibility complex (MHC) type I molecule. This patrolling mechanism is controlled by a large family of killer-cell immunoglobulin-like receptors (KIRs), among others, which bind and activate or inhibit NK cell cytotoxicity [7]. In human, at least two subsets of circulating NK cells have been described, the CD3CD56 ${ }^{\text {dim }}$ and CD3-CD56 ${ }^{\text {bright }}$ subsets. The CD56 ${ }^{\text {dim }}$ subset displays enhanced cytotoxicity whereas CD56 ${ }^{\text {bright }} \mathrm{NK}$ cells produce greater amounts of cytokines [8].

The role of NK cells in bacterial innate immunity took longer to be demonstrated. In contrast to phagocytes, the activation of NK cells by PAMPs can only occur through complex crosstalk with other immune cells that creates the proper cytokine microenvironment required for NK cells responsiveness [9]. Accordingly, similarly to any other cellular or molecular participant in infectious 
diseases, NK cells can play a 'guilty' or 'not guilty' role in the deleterious inflammatory process, depending on the circumstances and most probably the timing of the event. Thus, the same actors that contribute to fight infection can guiltily act in synergy, leading to acute deleterious inflammation by producing powerful inflammatory mediators [10]. This is particularly the case for interferon (IFN)- $\gamma$ and granulocyte-macrophage colony-stimulating factor (GM-CSF), two pro-inflammatory cytokines produced by NK cells [11].

The fact that pathogen sensors (for example, TLRs) were recently discovered to be expressed by NK cells has opened a new interest in their putative involvement in innate immune response to bacterial infections $[10,12]$. Recently, we have shown that both murine spleen and human blood NK cells express the bacterial sensors TLR2, TLR4 and TLR9 at the protein level and that they are responsive to their agonists in terms of IFN- $\gamma$ production in the presence of accessory cytokines [13-15]. In contrast to phagocytes, the activation of NK cells by PAMPs often requires complex crosstalk with other immune cells, as already shown with dendritic cells, polymorphonuclear cells, and so on. These accessory cells contribute to the cytokine microenvironment (for example, IL-12 and IL-18, cytokines that are strong NK activators and are produced by accessory cells as a parallel response to PAMPs) required for NK cell responsiveness [9]. Since 1984 [16], however, several studies and several lines of evidence have suggested a direct response of NK cells to PAMPs in the presence of an adequate cytokine environment, without the need for contact with accessory cells (see [10] for review). This reinforces the hypothesis that they can contribute to the overzealous inflammation in sepsis. CD69 is an activation marker upregulated upon stimulation of NK cells. We recently observed that the expression of TLR2, TLR4, and the early activation marker CD69 was upregulated in NK cells of septic patients compared to those of healthy volunteers, suggesting blood NK cells are activated during the early stages of sepsis. Interestingly, the expression of CD69 was even higher for SIRS patients, who have sterile inflammation, suggesting that CD69 might be a marker of acute inflammation rather than infection [14].

\section{NK cells as beneficial actors to fight infection}

Cytokines are key mediators required to orchestrate the anti-infectious process. Besides IFN- $\gamma$ and GM-CSF, NK cells can produce a large panel of cytokines, including TNF [17], that have been shown to be protective against different types of bacterial infections. It is not surprising then that many investigators have reported the beneficial contributions of NK cells in fighting infections. NK cells have been shown to be protective in different models, including infections with Mycobacterium avium, Shigella flexneri, Chlamidia trachomatis, Staphylococcus aureus, Pseudomonas aeruginosa, Listeria monocytogenes, Bordetella pertussis, Legionella pneumophila, Shigella flexneri, Salmonellae, Burkholderia pseudomallei, Mycobacterium tuberculosis, Rickettsiae, Yersinia enterocolitica, Chlamydophyla abortus or polymicrobial sepsis (see [10] for a review). In addition, NK cells were shown to be the main IFN- $\gamma$ producing cells in response to bacterial lipopolysaccharide (LPS) $[18,19]$. In addition, NK cells can also be the source of other anti-infectious mediators, such as the anti-microbial peptides and $\alpha$-defensins [20]. Furthermore, their beneficial contribution to protection occurs in combination with various cellular cross-talk with other immune cells that also are important in the process. Interestingly, IFN- $\gamma$ production, which underpins the effective NK cell response to infection, also underpins deleterious NK cell-mediated inflammation.

\section{NK cells as a guilty participant of the overzealous inflammation in sepsis}

Deleterious roles of NK cells have been reported in numerous animal models (see [10] for a review). Particularly, the capacity of NK cells to favor the inflammatory response, to promote tissue injury and to contribute to death has been reported after polymicrobial intraabdominal sepsis [21], Escherichia coli intraperitoneal injection [22], Streptococcus pyogenes intravenous injection [23], Ehrlichia-induced toxic shock-like syndrome [24] and in cytokine-induced SIRS [25]. Similarly to the association of the beneficial role of NK cells with their production of IFN- $\gamma$, their guilty role is also associated with their production of IFN- $\gamma$. Indeed, this cytokine, alone or in synergy with others, can lead to organ failure and death [2]. Likewise, GM-CSF can further amplify the inflammatory response and be deleterious [26,27], and even lead to death as shown in a human patient treated with this cytokine [28]. Other mediators can also contribute to the deleterious effects of NK cells, such as granzyme M [29].

More evidence of a guilty participation was reported in a murine polytrauma model (consisting of femur fracture, hemorrhagic shock and subsequent sepsis), in which NK cell depletion resulted in 50\% mortality reduction, a decrease of neutrophil infiltration in different compartments and lymphocyte apoptosis in the spleen [30]. In addition to the effect of PAMPs and cytokines, other mediators such as the anaphyloxin C5a can favor the inflammatory role of NK cells by increasing their IFN- $\gamma$ and TNF- $\alpha$ production and contributing to mortality during E. coli-induced sepsis [31].

\section{Natural mechanisms restricting excessive NK cell-mediated inflammation}

Concomitant with the pro-inflammatory response, a compensatory anti-inflammatory response occurs that 
can lead to a syndrome associated with increased sensitivity of patients to nosocomial infections [32,33]. This phenomenon prominently involves the refractoriness of monocytes/macrophages to challenge with LPS or other PAMPs, an observation also known as endotoxin tolerance [34]. Similarly, in murine spleen cells after experimental polymicrobial sepsis and in blood samples from ICU patients (bacterial sepsis or SIRS), IFN- $\gamma$ production in response to TLR agonists was lost, resembling the tolerance already described for monocytes [13,14]. In concert, NK cell immunosuppression was also observed in blood samples from trauma patients with brain injury, where poor NK cell recruitment into a BCG-induced granuloma model was noticed [35]. In parallel to the NK cell suppressed state in sepsis, T regulatory cells (Tregs) were shown to be increased as a percentage in the peripheral blood of patients compared with healthy controls [36-39].

Tregs are immune regulatory players that can inhibit the differentiation, activation, proliferation, cytokine secretion or migration of several other leukocytes (for example, by secretion of anti-inflammatory cytokines such as IL-10 and transforming growth factor (TGF)- $\beta 1$ ) [40]. Tregs have been shown to contribute to the antiinflammatory compensatory process, in part by inhibiting LPS-induced activation of monocytes by a Fas/Fas ligand death mechanism [41]. After experimental sepsis in mice, we recently showed that the tolerance to PAMPs, in terms of IFN- $\gamma$ production by purified NK cells, was reversed by depletion of Tregs or TGF- $\beta$ receptor inhibition prior to sepsis induction [13]. Accordingly, they also contribute to the obstruction of posterior tumor immunosurveillance, a classic NK cell effector function, in a profound immunosuppressive environment resulting from surviving severe sepsis [42].

Of note, measurements of NK cell function in humans have been made using NK cells exclusively from peripheral blood. Thus, one cannot speculate about NK cells from other tissues (for example, spleen and liver), which have not been evaluated and may behave differently. Nevertheless, the data available for spleen NK cells in mouse models show results very similar to human blood NK cells. Spleen NK cells need the same accessory cytokines for IFNY and GM-CSF production and might undergo endotoxin tolerance after sepsis [13]. In both mouse spleen and human blood, TLR2 and TLR4 are intracellular in naive NK cells $[13,14]$. Only a difference in the response to LPS has been observed, where human blood NK cells were found to be more responsive than murine spleen NK cells [43].

In agreement with other reports, we also observed that the number of circulating $\mathrm{NK} \mathrm{CD}_{56}{ }^{+}$cells was significantly decreased in sepsis and SIRS patients [44]. Moreover, we demonstrated for the first time that both
CD56 $6^{\text {bright }}$ and CD56 ${ }^{\text {dim }}$ subpopulations of CD56 $^{+}$cells were reduced in both SIRS and sepsis [14]. This decreased cell number is the reflection of a general lymphopenia, potentially due to the trafficking of NK cells to sites of infection $[21,45,46]$ or to apoptosis [47]. Interestingly, some reports suggest that NK cell percentages or counts are associated with patient outcome. In one study, CD4 ${ }^{+}$ lymphocyte lymphopenia and increased levels of NK cells in patient blood were associated with a survival benefit [48]. In contrast, other studies suggested that the increase of NK cell levels in blood was associated with early mortality $[49,50]$. Deeper investigations are still required to evaluate the predictive role of NK cell count for patient mortality before considering this information useful as a prognostic tool.

Regarding functional studies, NK cells were shown to have reduced cytotoxic activity in sepsis patients [51,52] and in SIRS patients following thermal and traumatic injury [53,54]. However, a recent review suggested a potential inflammatory participation of NK cells in SIRS and early sepsis, associated with an acquired dysfunction of cellular functions at a later stage that could favor nosocomial infections and mortality [55]. It has been shown that IFN- $\gamma$ production was altered in patients after elective surgery and severely impaired in patients with sepsis [56]. We also observed that the production of this cytokine was abolished ex vivo in whole blood of SIRS and sepsis patients after stimulation with accessory cytokines and TLR agonists [14]. In different experimental conditions, however, other studies have made different observations. Giannikopoulos and colleagues [57] showed that purified NK cells from sepsis patients exhibit enhanced IFN- $\gamma$ production after in vitro LPS stimulation. On the other hand, decreased IFN- $\gamma$ production by purified NK cells from sepsis or septic shock patients was observed when co-cultured with the K562 cell line, while cells purified from SIRS patients displayed increased IFN- $\gamma$ production [58]. In addition to NK cell lymphopenia and decreased IFN- $\gamma$ production in the blood of ICU patients, another study observed this cellular impairment preceding cytomegalovirus (CMV) reactivation in critically ill patients [59].

These complementary observations show that purified NK cells from patients behave differently to those stimulated in whole blood, and that IFN- $\gamma$ production depends on the culture conditions. The fact that purified NK cells can be stronger producers of IFN- $\gamma$ in certain conditions (during LPS [57] or K562 cell [58] stimulation) does not necessarily imply their participation in deleterious inflammation, as they are in fact present in a suppressive serum environment containing anti-inflammatory mediators (such as IL-10, TGF- $\beta 1$, corticoids, and so on) that might inactivate their inflammatory function [60]. Finally, decreased IFN- $\gamma$ production by NK cells in 


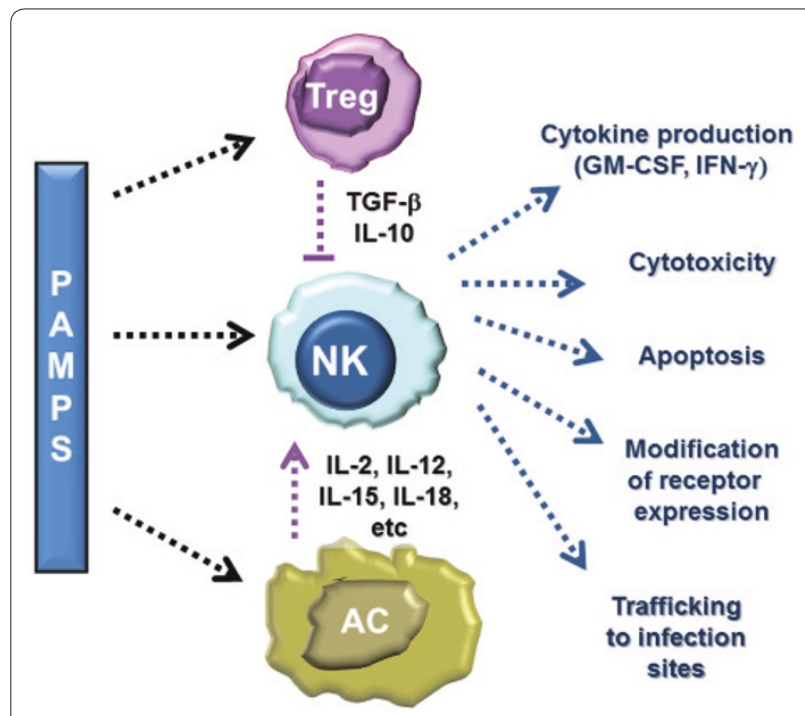

Figure1. Natural killer cell function during bacterial infection is modulated by the balance of factors into a complex environment. Accessory cells (AC), such as dendritic cells, monocytes or others, provide activating signals that trigger synergistic activation of natural killer (NK) cells together with pathogen-associated molecular patterns (PAMPs) to produce cytokines. On the other hand, activated T regulatory cells (Tregs) can counterbalance this by providing suppressive cytokines (for example, transforming growth factor (TGF)- $\beta$ and IL-10) to abolish NK cell activation. GM-CSF, granulocyte-macrophage colony-stimulating factor; IFN, interferon.

whole blood [14] and enhanced IFN- $\gamma$ production for purified cells $[57,58]$ together support the hypothesis that NK cells are not themselves under endotoxin tolerance (mechanism proposed for macrophages) but are rather inhibited by suppressive environmental factors (for example, TGF- $\beta$ and Tregs [13]). Taken together, this evidence reveals that Tregs are key players in the suppression of leukocytes during sepsis progression and that NK cells might not be guilty in the overzealous inflammatory reaction by being found to be suppressed during the disease.

\section{Conclusion}

Data gathered from recent reports show that peripheral NK cells are guilty of contributing to the overzealous inflammation process during sepsis by producing proinflammatory cytokines. However, NK cells might be considered not guilty on the basis of the balance of signals between accessory and inhibitory cells that can suppress their pro-inflammatory cytokine production (as suggested by Figure 1). Advances in NK cell research point to this cell population as a promising marker (cell counting and receptor expression (CD69, TLRs)) to be considered and evaluated during disease progression to predict patient outcome or provide supportive information for patient classification (SIRS or sepsis).

\section{Abbreviations}

GM-CSF, granulocyte-macrophage colony-stimulating factor; IFN, interferon; IL, interleukin; LPS, lipopolysaccharide; NK, natural killer; PAMP, pathogenassociated molecular pattern; SIRS, systemic inflammatory response syndrome; TGF, transforming growth factor; TLR, Toll-like receptor; TNF, tumor necrosis factor; Treg, T regulatory cells.

\section{Competing interests}

The authors declare that they have no competing interests.

\section{Acknowledgments}

The authors thank Dr Robin Friedman and Dr Liam Town for helpful comments on the manuscript. Authors are part of the CAPTAIN STUDY supported by Programme Hospitalier de Recherche Clinique (PHRC) and Institut MérieuxInstitut Pasteur. FSFG was funded by the international PhD program of Institut Pasteur and Paris University and a Pasteur-Weizmann fellowship.

\section{Author details}

'Unité Cytokines \& Inflammation, Département Infection et Epidemiologie, Institut Pasteur, 28 rue Dr. Roux, 75015 Paris, France. ${ }^{2}$ Current address: Laboratory of Immunology in Cancer and Infection, Queensland Institute of Medical Research, 300 Herston Rd, Brisbane, QLD 4006, Australia.

Published: 27 August 2013

\section{References}

1. Herzum I, Renz H: Inflammatory markers in SIRS, sepsis and septic shock. Curr Med Chem 2008, 15:581-587

2. Adib-Conquy M, Cavaillon JM: Stress molecules in sepsis and systemic inflammatory response syndrome. FEBS Lett 2007, 581:3723-3733.

3. Cavaillon JM, Adib-Conquy M: Bench-to-bedside review: endotoxin tolerance as a model of leukocyte reprogramming in sepsis. Crit Care 2006, 10:233.

4. Miller JFA, Brunner KT, Sprent J, Russell PJ, Mitchell GF: Thymus-derived cells as killer cells in cell-mediated immunity. Transplantat Proc 1971, 3:915-917.

5. Kiessling R, Klein E, Pross H, Wigzell H: "Natural" killer cells in the mouse. II. Cytotoxic cells with specificity for mouse Moloney leukemia cells. Characteristics of the killer cell. Eur J Immunol 1975, 5:117-121.

6. Macfarlan Rl, Burns WH, White DO: Two cytotoxic cells in peritoneal cavity of virus-infected mice: antibody-dependent macrophages and nonspecific killer cells. J Immunol 1977, 119:1569-1574.

7. Moretta A, Bottino C, Vitale M, Pende D, Biassoni R, Mingari MC, Moretta L: Receptors for HLA class-I molecules in human natural killer cells. Annu Rev Immunol 1996, 14:619-648.

8. Huntington ND, Vosshenrich CAJ, Di Santo JP: Developmental pathways that generate natural-killer-cell diversity in mice and humans. Nat Rev Immunol 2007, 7:703-714.

9. Newman KC, Riley EM: Whatever turns you on: accessory-cell-dependent activation of NK cells by pathogens. Nat Rev Immuno/ 2007, 7:279-291.

10. Souza-Fonseca-Guimaraes F, Adib-Conquy M, Cavaillon JM: Natural Killer (NK) cells in antibacterial innate immunity: angels or devils? Mol Med 2012, 18:270-285.

11. Doherty GM, Lange JR, Langstein HN, Alexander HR, Buresh CM, Norton JA: Evidence for IFN-gamma as a mediator of the lethality of endotoxin and tumor necrosis factor-alpha. J Immuno/ 1992, 149:1666-1670.

12. Bohannon J, Guo Y, Sherwood ER: The role of natural killer cells in the pathogenesis of sepsis: the ongoing enigma. Crit Care 2012, 16:185.

13. Souza-Fonseca-Guimaraes F, Parlato M, Fitting C, Cavaillon JM, Adib-Conquy M: NK cell tolerance to TLR agonists mediated by regulatory T cells after polymicrobial sepsis. J Immunol 2012, 188:5850-5858.

14. Souza-Fonseca-Guimaraes F, Parlato M, Philippart F, Misset B, Cavaillon JM, Adib-Conquy M, Study Group C: Toll-like receptors expression and interferongamma production by NK cells in human sepsis. Crit Care 2012, 16:R206.

15. Souza-Fonseca-Guimaraes F, Parlato M, de Oliveira RB, Golenbock D, Fitzgerald K, Shalova IN, Biswas SK, Cavaillon JM, Adib-Conquy M: Interferon-gamma and granulocyte/monocyte colony-stimulating factor production by natural killer cells involves different signaling pathways and the adaptor stimulator of interferon genes (STING). J Biol Chem 2013, 288:10715-10721.

16. Goguel AF, Payelle B, Quan PC, Lespinats G: Stimulation of one particular subset of natural killer cells by peptidoglycans extracted from gram-positive bacteria. J Nat/ Cancer Inst 1984, 73:697-703.

17. Cuturi MC, Murphy M, Costa-Giomi MP, Weinmann R, Perussia B, Trinchieri G: Independent regulation of tumor necrosis factor and lymphotoxin 
production by human peripheral blood lymphocytes. J Exp Med 1987, 165:1581-1594.

18. Kim S, lizuka K, Aguila HL, Weissman IL, Yokoyama WM: In vivo natural killer cell activities revealed by natural killer cell-deficient mice. Proc Natl Acad Sci U SA 2000, 97:2731-2736.

19. Varma TK, Lin CY, Toliver-Kinsky TE, Sherwood ER: Endotoxin-induced gamma interferon production: contributing cell types and key regulatory factors. Clin Diagn Lab Immunol 2002, 9:530-543.

20. Agerberth B, Charo J, Werr J, Olsson B, Idali F, Lindbom L, Kiessling R, Jornvall H, Wigzell $\mathrm{H}$, Gudmundsson $\mathrm{GH}$ : The human antimicrobial and chemotactic peptides LL-37 and alpha-defensins are expressed by specific lymphocyte and monocyte populations. Blood 2000, 96:3086-3093.

21. Etogo AO, Nunez J, Lin CY, Toliver-Kinsky TE, Sherwood ER: NK but not CD1restricted NKT cells facilitate systemic inflammation during polymicrobial intra-abdominal sepsis. J Immunol 2008, 180:6334-6345.

22. Badgwell B, Parihar R, Magro C, Dierksheide J, Russo T, Carson WE: Natural killer cells contribute to the lethality of a murine model of Escherichia coli infection. Surgery 2002, 132:205-212.

23. Goldmann O, Chhatwal GS, Medina E: Contribution of natural killer cells to the pathogenesis of septic shock induced by Streptococcus pyogenes in mice. J Infect Dis 2005, 191:1280-1286.

24. Stevenson HL, Estes MD, Thirumalapura NR, Walker DH, Ismail N: Natural killer cells promote tissue injury and systemic inflammatory responses during fatal Ehrlichia-induced toxic shock-like syndrome. Am J Pathol 2010, 177:766-776.

25. Carson WE, Yu H, Dierksheide J, Pfeffer K, Bouchard P, Clark R, Durbin J, Baldwin AS, Peschon J, Johnson PR, Ku G, Baumann H, Caligiuri MA: A fatal cytokineinduced systemic inflammatory response reveals a critical role for NK cells. J Immuno/ 1999, 162:4943-4951.

26. Bozinovski S, Jones JE, Vlahos R, Hamilton JA, Anderson GP: Granulocyte/ macrophage-colony-stimulating factor (GM-CSF) regulates lung innate immunity to lipopolysaccharide through akt/Erk activation of nfkb and AP-1 in vivo. J Biol Chem 2002, 277:42808-42814.

27. Wollin L, Uhlig S, Nusing R, Wendel A: Granulocyte-macrophage colonystimulating factor amplifies lipopolisaccharide-induced bronchoconstriction by a neutrophil- and cyclooxigenase 2-dependent mechanism. Am J Respir Crit Care Med 2001, 163:443-450.

28. Verhoef $\mathrm{G}$, Boogaerts $\mathrm{M}$ : Treatment with granulocyte-macrophage colony stimulating factor and the adult respiratory distress syndrome. Am J Hematol 1991, 36:285-287.

29. Anthony DA, Andrews D, Chow M, Watt SV, House C, Akira S, Bird PI, Trapani JA, Smyth MJ: A role of granzyme M in TLR4-driven inflammation and endotoxicosis. J Immunol 2010, 185:1794-1803.

30. Barkhausen T, Frerker C, Putz C, Pape HC, Krettek C, van Griensven M: Depletion of NK cells in a murine polytrauma model is associated with improved outcome and a modulation of the inflammatory response. Shock 2008 30:401-410.

31. Fusakio ME, Mohamed JP, Laumonnier Y, Hoebe K, Kohl J, Mattner J: C5a regulates NKT and NK cell function in sepsis. J Immuno/ 2011, 187:5805-5812.

32. Cavaillon JM, Adib-Conquy M, Cloez-Tayarani I, Fitting C: Immunodepression in sepsis and SIRS assessed by ex vivo cytokine production is not a generalized phenomenon: a review. J Endotox Res 2001, 7:85-93.

33. Adib-Conquy $M$, Cavaillon JM: Compensatory anti-inflammatory response syndrome. Thrombosis Haemostasis 2009, 101:36-47.

34. Cavaillon JM, Adrie C, Fitting C, Adib-Conquy M: Reprogramming of circulatory cells in sepsis and SIRS. J Endotox Res 2005, 11:311-320.

35. Deknuydt F, Roquilly A, Cinotti R, Altare F, Asehnoune K: An in vitro model of Mycobacterial granuloma to investigate the immune response in braininjuried patients. Crit Care Med 2013, 41:245-254.

36. Venet F, Pachot A, Debard AL, Bohe J, Bienvenu J, Lepape A, Monneret G: Increased percentage of CD4+CD25+regulatory T cells during septic shock is due to the decrease of CD4+CD25-lymphocytes. Crit Care Med 2004, 32:2329-2331.

37. Venet F, Chung CS, Kherouf H, Geeraert A, Malcus C, Poitevin F, Bohe J, Lepape A, Ayala A, Monneret G: Increased circulating regulatory T cells (CD4(+) CD25(+)CD127(-)) contribute to lymphocyte anergy in septic shock patients. Intensive Care Med 2009, 35:678-686.

38. Monneret G, Debard AL, Venet F, Bohe J, Hequet O, Bienvenu J, Lepape A: Marked elevation of human circulating CD4+CD25+ regulatory T cells in sepsis-induced immunoparalysis. Crit Care Med 2003, 31:2068-2071.
39. Kessel A, Bamberger E, Masalha M, Toubi E: The role of T regulatory cells in human sepsis. J Autoimmun 2009, 32:211-215.

40. Campbell DJ, Koch MA: Phenotypical and functional specialization of FOXP3(+) regulatory T cells. Nat Rev Immunol 2011, 11:119-130.

41. Venet F, Pachot A, Debard AL, Bohe J, Bienvenu J, Lepape A, Powell WS, Monneret G: Human CD4(+)CD25(+) regulatory T lymphocytes inhibit lipopolysaccharide-induced monocyte survival through a Fas/Fas liganddependent mechanism. J Immuno/ 2006, 177:6540-6547.

42. Cavassani KA, Carson WF 4th, Moreira AP, Wen H, Schaller MA, Ishii M, Lindell DM, Dou Y, Lukacs NW, Keshamouni VG, Hogaboam CM, Kunkel SL: The post sepsis-induced expansion and enhanced function of regulatory $T$ cells create an environment to potentiate tumor growth. Blood 2010, 115:4403-4411.

43. Kanevskiy LM, Telford W, Sapozhnikov AM, Kovalenko El: Lipopolisaccharide induces IFN-gamma production in human NK cells. Front Immuno/ 2013, in press.

44. Holub M, Kluckova Z, Helcl M, Prihodov J, Rokyta R, Beran O: Lymphocyte subset numbers depend on the bacterial origin of sepsis. Clin Microbiol Infect 2003, 9:202-211.

45. Gregoire C, Chasson L, Luci C, Tomasello E, Geissmann F, Vivier E, Walzer T: The trafficking of natural killer cells. Immunol Rev 2007, 220:169-182.

46. Herzig DS, Driver BR, Fang GP, Toliver-Kinsky TE, Shute EN, Sherwood ER: Regulation of lymphocyte trafficking by CXC chemokine receptor 3 during septic shock. Am J Respir Crit Care Med 2012, 185:291-300.

47. Hotchkiss RS, Nicholson DW: Apoptosis and caspases regulate death and inflammation in sepsis. Nat Rev Immunol 2006, 6:813-822

48. Giamarellos-Bourboulis EJ, Tsaganos T, Spyridaki E, Mouktaroudi M, Plachouras D, Vaki I, Karagianni V, Antonopoulou A, Veloni V, Giamarellou H: Early changes of CD4-positive lymphocytes and NK cells in patients with severe Gramnegative sepsis. Crit Care 2006, 10:R166

49. Andaluz-Ojeda D, Iglesias V, Bobillo F, Almansa R, Rico L, Gandía F, Loma AM, Nieto C, Diego R, Ramos E, Nocito M, Resino S, Eiros JM, Tamayo E, de Lejarazu $\mathrm{RO}$, Bermejo-Martin JF: Early natural killer cell counts in blood predict mortality in severe sepsis. Crit Care 2011, 15:R243.

50. de Pablo R, Monserrat J, Reyes E, Diaz D, Rodriguez-Zapata M, de la Hera A Prieto A, Alvarez-Mon M: Sepsis-induced acute respiratory distress syndrome with fatal outcome is associated to increased serum transforming growth factor beta-1 levels. Eur J Intern Med 2012, 23:358-362.

51. Maturana P, Puente J, Miranda D, Sepulveda C, Wolf ME, Mosnaim AD: Naturalkiller-cel activity in patients with septic shock. J Crit Care 1991, 6:42-45.

52. Georgeson GD, Szony BJ, Streitman K, Kovacs A, Kovacs L, Laszlo A: Natural killer cell cytotoxicity is deficient in newborns with sepsis and recurrent infections. Eur J Pediatr 2001, 160:478-482

53. Blazar BA, Rodrick ML, Omahony JB, Wood JJ, Bessey PQ, Wilmore DW, Mannick $J A$ : Suppression of natural-killer-cell function in humans following thermal and traumatic injury. J Clin Immunol 1986, 6:26-36.

54. Klimpel GR, Herndon DN, Fons M, Albrecht T, Asuncion MT, Chin R, MD S: Defective NK cell-activity following thermal-injury. Clin Exp Immunol 1986, 66:384-392.

55. Chiche L, Forel JM, Thomas G, Farnarier C, Vely F, Bléry M, Papazian L, Vivier E. The role of natural killer cells in sepsis. J Biomed Biotechnol 2011, 2011:986491.

56. Hiraki S, Ono S, Kinoshita M, Tsujimoto H, Seki S, Mochizuki H: Interleukin-18 restores immune suppression in patients with nonseptic surgery, but not with sepsis. Am J Surg 2007, 193:676-680.

57. Giannikopoulos G, Kalpakou G, Makaritsis K, Panou C, Papadomichelakis E, Sinapidis D, Theodotou A, Tzagkaraki A, Giamarellos-Bourboulis EJ: The functional role of natural killer cells early in clinical sepsis. APMIS 2013, 121:329-336.

58. Forel JM Chiche L, Thomas G, Mancini J, Farnarier C, Cognet C, Guervilly C, Daumas A, Vély F, Xéridat F, Vivier E, Papazian L: Phenotype and functions of natural killer cells in critically-ill septic patients. PLoS One 2012, 7:e50446.

59. Chiche L, Forel JM, Thomas G, Farnarier C, Cognet C, Guervilly C, Zandotti C, Vély F, Roch A, Vivier E, Papazian L: Interferon- $\gamma$ production by natural killer cells and cytomegalovirus in critically ill patients. Crit Care Med 2012, 40:3162-3169.

60. Cavaillon JM: "Septic plasma", an immunosuppressive milieu. Am J Respir Crit Care Med 2002, 166:1417-1422.

doi:10.1186/cc12700

Cite this article as: Souza-Fonseca-Guimaraes F, et al:: Bench-to-bedside review: Natural killer cells in sepsis - guilty or not guilty?. Critical Care 2013, $17: 235$. 


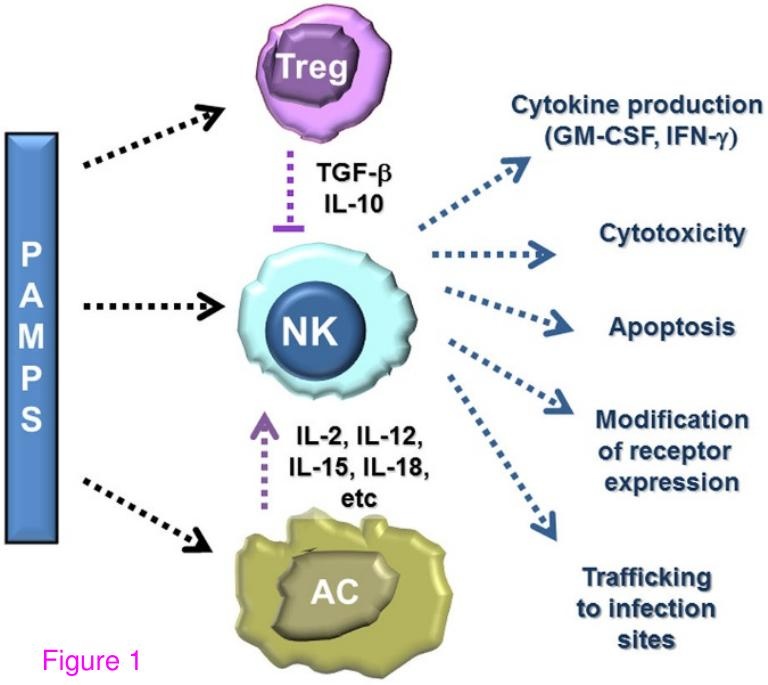

